\title{
Influence of Doping on the Magnetic Properties and Local Microstructures in Fe-Doped $\mathrm{YMnO}_{3}$
}

\author{
Xiaopeng Ge1, Jiaou Wang², Kurash Ibrahim², Wenbo Yang1, Xueguang Dong1, Qi Li ${ }^{*}$ \\ ${ }^{1}$ Department of Physics, Southeast University, Nanjing, China \\ ${ }^{2}$ Beijing Synchrotron Radiation Facility, Institute of High Energy Physics, Chinese Academy of Sciences, Beijing, \\ China \\ Email: ${ }^{*}$ qli@seu.edu.cn
}

Received 25 November 2014

\begin{abstract}
Polycrystalline $\mathrm{YMn}_{1-\mathrm{x}} \mathrm{Fe}_{\mathrm{x}} \mathrm{O}_{3}(0<\mathrm{x}<0.1)$ samples are synthesized by solid-state reaction method and characterized by X-ray diffraction. The X-ray diffraction patterns indicate that $\mathrm{YMn}_{1-\mathrm{x}} \mathrm{Fe}_{\mathrm{x}} \mathrm{O}_{3}$ compounds maintain hexagonal structure with space group of $\mathrm{p} 6_{3} \mathrm{~cm}$. Ferromagnetism of $\mathrm{YMn}_{1-\mathrm{x}} \mathrm{Fe}_{\mathrm{x}} \mathrm{O}_{3}$ increases with increasing doping concentration of $\mathrm{Fe}^{3+}$, attributed to the suppression of the frustration and the change of the Mn-O bond length certificated by XAS analysis.
\end{abstract}

\section{Keywords}

Multiferroics, $\mathrm{YMn}_{1-\mathrm{x}} \mathrm{Fe}_{\mathrm{x}} \mathrm{O}_{3}$, Hybrid States, X-Ray Absorption Spectra

\section{Introduction}

Multiferroic materials simultaneously possess magnetic and ferroelectric orders which co-exist and couple with each other [1]. They are able to put the electrical, magnetic and optical properties together and suitable to design new multi-functional electronic information storage elements. Multiferroic materials have become one of the most active areas in the field of materials science. Hexagonal $\mathrm{RMnO}_{3}(\mathrm{R}=\mathrm{Y}$, Ho-Lu) materials occupy a very important position in the single-phase multiferroic materials. They have novel properties, indicating the potential in the material research and applications [2]. Therefore hexagonal manganites $\mathrm{YMnO}_{3}$ have attracted widespread attention in recent years. However, because $\mathrm{YMnO}_{3}$ exhibits the coupling of antiferromagnetism and ferroelectricity, such multiferroic is not very sensitive to the applied external electromagnetic fields [3]; thereby it is the purpose of many researchers to increase the ferromagnetic property of $\mathrm{YMnO}_{3}$.

As an effective research tool, ion doping in A site (i.e. Y site) or B site (i.e. Mn site) of $\mathrm{YMnO}_{3}$ is often used to change the ferromagnetic property of $\mathrm{YMnO}_{3}$ [4]. Some research teams have selected kinds of ions replacing the $\mathrm{Y}^{3+}$ to modulate the antiferromagnetic order of $\mathrm{YMnO}_{3}$, such as $\mathrm{Lu}^{3+}, \mathrm{Sr}^{2+}$. It will make partial antiferromagnetic order convert to ferromagnetic properties in the compounds where $\mathrm{Y}^{3+}$ was replaced by $\mathrm{Lu}^{3+}$ or $\mathrm{Sr}^{2+}$ [5]

\footnotetext{
*Corresponding author.
}

How to cite this paper: Ge, X.P., Wang, J., Ibrahim, K., Yang, W.B., Dong, X.G. and Li, Q. (2015) Influence of Doping on the Magnetic Properties and Local Microstructures in Fe-Doped $\mathrm{YMnO}_{3}$. Journal of Applied Mathematics and Physics, 3, 262-266. http://dx.doi.org/10.4236/jamp.2015.32038 
[6]. Transition metal ions replacing the $\mathrm{Mn}^{3+}$ in the $\mathrm{B}$ site of $\mathrm{YMnO}_{3}$ is another way to modulate the antiferromagnetic order. Several current experiments have successfully synthesized samples in which the $\mathrm{Mn}^{3+}$ in the $\mathrm{B}$ site of $\mathrm{YMnO}_{3}$ is replaced by kinds of ions, such as $\mathrm{Fe}^{3+}, \mathrm{Al}^{3+}, \mathrm{Cu}^{2+}$, $\mathrm{Ti}^{3+}$, etc. [7]-[10]. Y. J. Yoo et al., who have synthesized polycrystalline $\mathrm{Cr}$-doped $\mathrm{YMnO}_{3}$ with hexagonal structure and space group $\mathrm{P}_{3} \mathrm{~cm}$, found that the magnetic transition temperature increased as the concentration of $\mathrm{Cr}$ increased [11]. Indeed, it will make the ferromagnetic property of $\mathrm{YMnO}_{3}$ increase significantly by the substitution of the $\mathrm{Mn}^{3+}$ with transition metal ions in the $\mathrm{YMnO}_{3}$ samples. However, the reason of the change of magnetism is still not explained clearly. Compared to previous studies about $\mathrm{YMnO}_{3}$ samples, this paper will explain the change of magnetism when the $\mathrm{Fe}^{3+}$ replaces the $\mathrm{Mn}^{3+}$ in the $\mathrm{B}$ site of $\mathrm{YMnO}_{3}$ samples according to XAS of O K edge and $\mathrm{Mn} \mathrm{L}$ edge.

\section{Experimental Details}

Polycrystalline $\mathrm{YMn}_{1-\mathrm{x}} \mathrm{Fe}_{\mathrm{x}} \mathrm{O}_{3}(0<\mathrm{x}<0.1)$ samples were prepared by a standard solid-state reaction. The analytical pure $\mathrm{Y}_{2} \mathrm{O}_{3}, \mathrm{MnO}_{2}$ and $\mathrm{Fe}_{2} \mathrm{O}_{3}$ were weighed according to stoichiometric proportion. The mixed powder was put into an agate mortar milling 5 hours with petroleum ether. The milled powder was transferred into a corundum crucible in a tube furnace. The powder was sintered $2 \mathrm{~h}$ at $1100^{\circ} \mathrm{C}$ then heated to $1370^{\circ} \mathrm{C}$, maintaining 24 hours. Taking out the powder and milling for 2 hours, we can obtain the $\mathrm{YMn}_{1-\mathrm{x}} \mathrm{Fe}_{\mathrm{x}} \mathrm{O}_{3}(0<\mathrm{x}<0.1)$ samples. The crystal structures of the samples were examined by $\mathrm{X}$-ray diffraction (XRD) with $\mathrm{Cu} \mathrm{K} \alpha$ radiation (Rigaku Smart Lab3, Japan). The magnetic properties of $\mathrm{YMn}_{1-\mathrm{x}} \mathrm{Fe}_{\mathrm{x}} \mathrm{O}_{3}$ were measured by SQUID-VSM (Quantum Design, USA). In order to observe the change of $\mathrm{Y}-\mathrm{O}, \mathrm{Mn}-\mathrm{O}$ hybrid states, the $\mathrm{X}$-ray absorption spectroscopy (XAS) of O K edge and Mn L edge of $\mathrm{YMn}_{1-\mathrm{x}} \mathrm{Fe}_{\mathrm{x}} \mathrm{O}_{3}(0<\mathrm{x}<0.1)$ samples were measured utilizing total electron yield (TEY) mode in photoemission spectroscopy experiment station of Beijing Synchrotron Radiation Facility, Chinese Academy of Sciences.

\section{Results and Discussion}

XRD patterns of powder samples $\mathrm{YMn}_{1-\mathrm{x}} \mathrm{Fe}_{\mathrm{x}} \mathrm{O}_{3}(0<\mathrm{x}<0.1)$ at room temperature are measured as shown in Figure 1. XRD patterns of $\mathrm{YMn}_{1-\mathrm{x}} \mathrm{Fe}_{\mathrm{x}} \mathrm{O}_{3}$ illustrate that all samples are in single phase with hexagonal lattice structure, space group $\mathrm{P}_{3} \mathrm{~cm}$. It illustrates that $\mathrm{Fe}^{3+}$ ion replaces the lattice position of $\mathrm{Mn}^{3+}$ ion and doesn't change the lattice structures of $\mathrm{YMn}_{1-\mathrm{x}} \mathrm{Fe}_{\mathrm{x}} \mathrm{O}_{3}$ samples, with the incorporation of $\mathrm{Fe}^{3+}$ ion. Because $\mathrm{Fe}^{3+}$ ionic radius $(0.49 \AA)$ is smaller than the $\mathrm{Mn}^{3+}$ ionic radius $(0.58 \AA)$, the lattice structures of $\mathrm{YMn}_{1-\mathrm{x}} \mathrm{Fe}_{\mathrm{x}} \mathrm{O}_{3}$ samples have a slight contraction. This change can be found from the diffraction peaks of $\mathrm{YMn}_{1-\mathrm{x}} \mathrm{Fe}_{\mathrm{x}} \mathrm{O}_{3}$ samples. The diffraction peak (112) of $\mathrm{YMn}_{0.95} \mathrm{Fe}_{0.05} \mathrm{O}_{3}$ shifts toward the higher angle with respect to that of $\mathrm{YMnO}_{3}$ (as inset of Figure 1). The contraction of lattice structure will lead to the change of Y-O, Mn-O hybrid states and Y, Mn ligand structure, which will affect the bond lengths of $\mathrm{Y}-\mathrm{O}$ and Mn-O. These changes will affect the magnetic order of $\mathrm{YMn}_{1-\mathrm{x}} \mathrm{Fe}_{\mathrm{x}} \mathrm{O}_{3}(0<\mathrm{x}<0.1)$ samples.

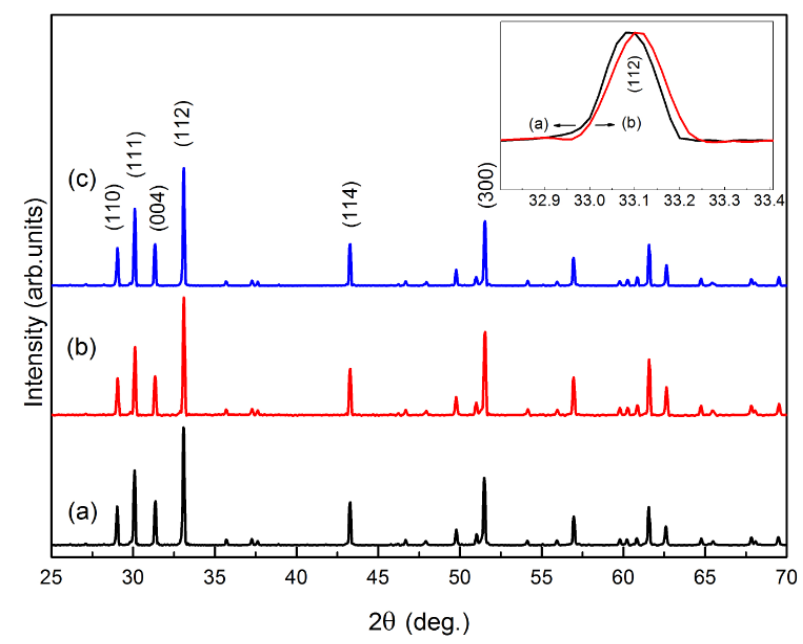

Figure 1. XRD patterns of $\mathrm{YMn}_{1-\mathrm{x}} \mathrm{Fe}_{\mathrm{x}} \mathrm{O}_{3}(0<\mathrm{x}<0.1)$ samples. (a) $\mathrm{x}=0$; (b) $\mathrm{x}=0.05$; (c) $\mathrm{x}=0.08$. 
In order to observe the magnetism change of $\mathrm{YMn}_{1-\mathrm{x}} \mathrm{Fe}_{\mathrm{x}} \mathrm{O}_{3}$ samples, field cooled (FC) temperature dependent magnetization (M-T) curves were measured from $30 \mathrm{~K}$ to $300 \mathrm{~K}$ with cooling field of 5000 Oe as shown in Figure 2. The magnetism of $\mathrm{YMn}_{1-\mathrm{x}} \mathrm{Fe}_{\mathrm{x}} \mathrm{O}_{3}$ samples are significantly enhanced, which is attributed to the incorporation of $\mathrm{Fe}^{3+}$ ion. Since Mn trimer arrangement exists the magnetic frustration effect (shown in Figure 2(b)), the magnetic frustration effect is relieved when $\mathrm{Fe}^{3+}$ ions partially replace $\mathrm{Mn}^{3+}$ ions in the B-site of crystal lattice. And $\mathrm{Fe}^{3+}$ ion having five $3 \mathrm{~d}$ electrons will enhance the magnetism of $\mathrm{YMn}_{1-\mathrm{x}} \mathrm{Fe}_{\mathrm{x}} \mathrm{O}_{3}$ samples. In addition, due to $\mathrm{Fe}^{3+}$ ions doping, the lattice structures of $\mathrm{YMn}_{1-\mathrm{x}} \mathrm{Fe}_{\mathrm{x}} \mathrm{O}_{3}$ samples shrink slightly, causing the magnetic exchange interaction to be enhanced.

Figure 3 shows the XAS of $\mathrm{O} K$ edge of $\mathrm{YMn}_{1-\mathrm{x}} \mathrm{Fe}_{\mathrm{x}} \mathrm{O}_{3}$ samples which illustrate the hybrid states between $\mathrm{O}$ $2 \mathrm{p}$ and $\mathrm{Mn} 3 \mathrm{~d}, \mathrm{Y} 4 \mathrm{~d}, \mathrm{Mn} 4 \mathrm{sp} / \mathrm{Y}$ 5sp. The absorption spectra of the O 2p-Mn 3d hybrid states can be refined to four peaks, namely $a_{1 g} \uparrow, e_{1 g} \downarrow, e_{2 g} \downarrow, a_{1 g} \downarrow[12]$. O 2p-Y 4d electron orbitals also have a strong hybridization as shown by the XAS of O K edge. $\mathrm{Mn}^{3+}$ ion is surrounded by 5 Oxygen atoms, forming bipyramid structure $\mathrm{MnO}_{5}$, as shown in Figure 4(a).

The ferroelectric transition temperature $\mathrm{T}_{\mathrm{C}}$ of $\mathrm{YMnO}_{3}$ is about $900 \mathrm{~K}$. When paraelectric phase is transformed to ferroelectric phase for $\mathrm{YMnO}_{3}$, the bipyramid $\mathrm{MnO}_{5}$ will be tilted, as shown in Figure 4(b) [13]. The ferroe-

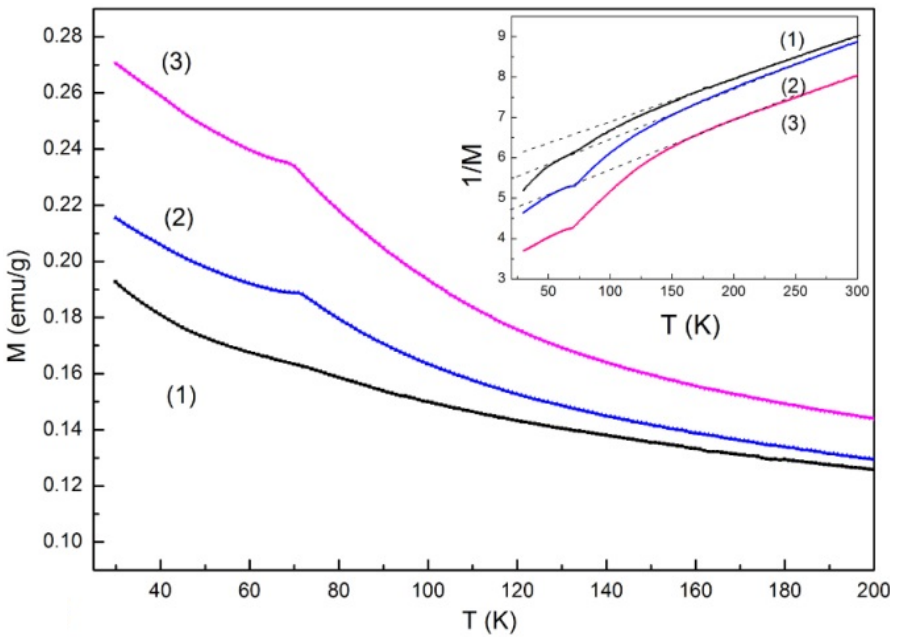

(a)

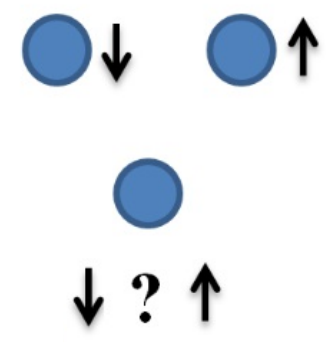

(b)

Figure 2. (a) The field cooled (FC) temperature dependent magnetization (M-T) curves of $\mathrm{YMn}_{1-\mathrm{x}} \mathrm{Fe}_{\mathrm{x}} \mathrm{O}_{3}$ $(0<x<0.1)$ samples. (1) $x=0$, (2) $x=0.05$, (3) $x=0.08$; (b) Schematic diagram of the magnetic frustration effect in $\mathrm{Mn}$ trimer arrangement of $\mathrm{YMnO}_{3}$.

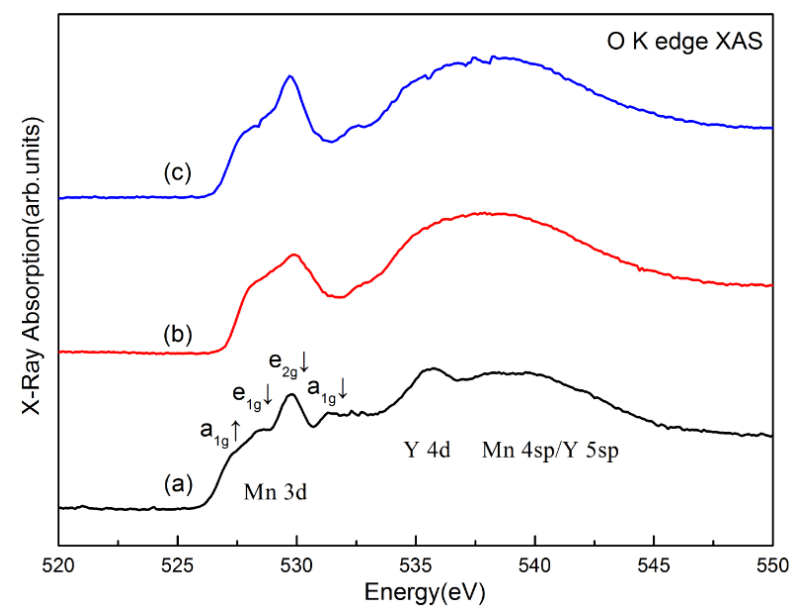

Figure 3. The X-ray absorption spectroscopy (XAS) of O K edge of $\mathrm{YMn}_{1-\mathrm{x}} \mathrm{Fe}_{\mathrm{x}} \mathrm{O}_{3}(0<\mathrm{x}<0.1)$ samples. (a) $\mathrm{x}=0$; (b) $\mathrm{x}=0.05$; (c) $\mathrm{x}=0.08$. 
lectric order of $\mathrm{YMnO}_{3}$ is induced by the inclined bipyramid $\mathrm{MnO}_{5}$ which leads to the orbital hybridization of $\mathrm{O}$ $2 \mathrm{p}-\mathrm{Y} 4 \mathrm{~d}$ enhanced. As shown in Figure 3, due to $\mathrm{Fe}^{3+}$ ion doped, the intensity of $\mathrm{e}_{1 \mathrm{~g}} \downarrow$ and $\mathrm{e}_{2 \mathrm{~g}} \downarrow$ peaks are enhanced which indicates the orbital hybridization of $\mathrm{O} 2 \mathrm{p}-\mathrm{Mn} 3 \mathrm{~d}$ is enhanced. The change in the intensity of $\mathrm{e}_{1 \mathrm{~g}} \downarrow$ and $\mathrm{e}_{2 \mathrm{~g}} \downarrow$ peaks also shows that the structural distortion of $\mathrm{MnO}_{5}$ has been minorly changed. The structural distortion of $\mathrm{MnO}_{5}$ will also affect the coordination environment of $\mathrm{Y}^{3+}$ ion, resulting in the change of $\mathrm{O} 2 \mathrm{p}-\mathrm{Y} 4 \mathrm{~d}$ orbital hybridization. The absorption spectra of $\mathrm{O} 2 \mathrm{p}-\mathrm{Y} 4 \mathrm{~d}$ are enhanced in intensity, as shown in Figure 3, consistent with our discussion.

Because O 2p-Mn 3d orbital hybridization is changed, the electronic orbital of Mn 3d presents a more complex structure in $\mathrm{YMn}_{1-\mathrm{x}} \mathrm{Fe}_{\mathrm{x}} \mathrm{O}_{3}(0<\mathrm{x}<0.1)$ samples. The electronic orbital of Mn 3d splits into $\mathrm{e}_{1 \mathrm{~g}}, \mathrm{e}_{2 \mathrm{~g}}, \mathrm{a}_{1 \mathrm{~g}}$ (as shown in Figure 4(c)) [12]. As shown in Figure 5, the lower energy segments of $M n 3 d L_{3}$ absorption spectra peak are significantly enhanced in $\mathrm{YMn}_{0.95} \mathrm{Fe}_{0.05} \mathrm{O}_{3}$ and $\mathrm{YMn}_{0.92} \mathrm{Fe}_{0.08} \mathrm{O}_{3}$ samples compared to that of $\mathrm{YMnO}_{3}$ sample. This shows that there are more empty electronic states in the low energy states (such as $\mathrm{e}_{1 \mathrm{~g}}, \mathrm{e}_{2 \mathrm{~g}}$ ), due to $\mathrm{Fe}^{3+}$ doping, which is consistent with the situation of $\mathrm{O} \mathrm{K}$ edge absorption spectra. The electronic orbital of $\mathrm{Mn}$ $3 \mathrm{~d}$ is closely related to magnetic exchange interaction and lattice distortion of $\mathrm{MnO}_{5}$.

\section{Conclusion}

Polycrystalline $\mathrm{YMn}_{1-\mathrm{x}} \mathrm{Fe}_{\mathrm{x}} \mathrm{O}_{3}(0<\mathrm{x}<0.1)$ samples were prepared by a standard solid-state reaction. The lattice structures of hexagonal $\mathrm{YMn}_{1-\mathrm{x}} \mathrm{Fe}_{\mathrm{x}} \mathrm{O}_{3}(0<\mathrm{x}<0.1)$ samples are unchanged with $\mathrm{Fe}^{3+}$ doping. The magnetic properties of $\mathrm{YMn}_{1-\mathrm{x}} \mathrm{Fe}_{\mathrm{x}} \mathrm{O}_{3}$ samples are significantly enhanced, and can be attributed to doping $\mathrm{Fe}^{3+}$ ion in $\mathrm{YMnO}_{3}$. According to XRD patterns, it can be obtained that the lattice structures of $\mathrm{YMn}_{1-\mathrm{x}} \mathrm{Fe}_{\mathrm{x}} \mathrm{O}_{3}(0<\mathrm{x}<0.1)$

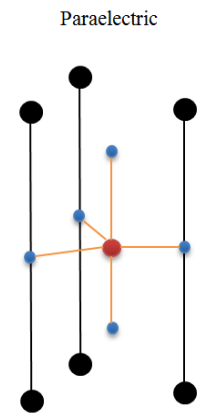

(a)

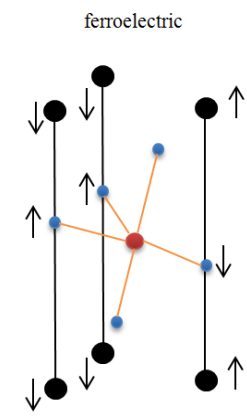

(b)
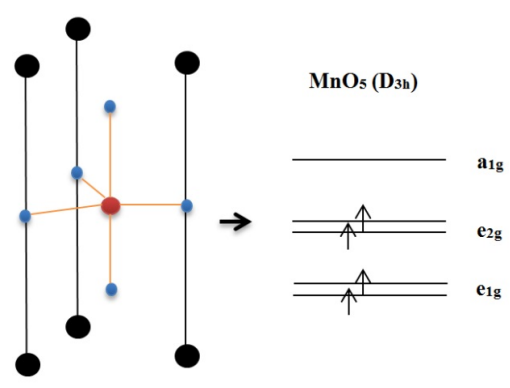

(c)

Figure 4. (a) Crystal structure of hexagonal of $\mathrm{YMnO}_{3}$ with paraelectric phase; (b) Crystal structure of hexagonal of $\mathrm{YMnO}_{3}$ with ferroelectric phase; (c) Schematic crystal field splittings for $\mathrm{MnO}_{5}\left(\mathrm{D}_{3 \mathrm{~h}}\right)$.

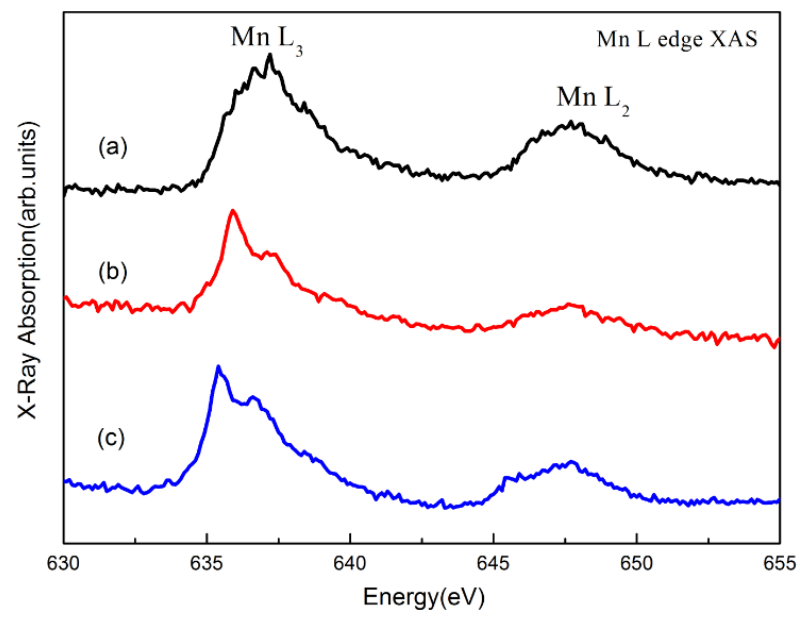

Figure 5. The X-ray absorption spectroscopy (XAS) of Mn L edge of $\mathrm{YMn}_{1-\mathrm{x}} \mathrm{Fe}_{\mathrm{x}} \mathrm{O}_{3}(0<\mathrm{x}<0.1)$ samples. (a) $\mathrm{x}=0$; (b) $\mathrm{x}=$ 0.05 ; (c) $\mathrm{x}=0.08$. 
samples slightly shrink. Based on O K edge and Mn L edge XAS absorption spectra of $\mathrm{YMn}_{1-\mathrm{x}} \mathrm{Fe}_{\mathrm{x}} \mathrm{O}_{3}(0<\mathrm{x}<$ 0.1 ) samples, it can be obtained that distortion occurs on the surrounded ligand structures of $\mathrm{Y}^{3+}$ and $\mathrm{Mn}^{3+}$ and that the orbital hybridization of $\mathrm{Y}-\mathrm{O}$ and $\mathrm{Mn}-\mathrm{O}$ are enhanced as $\mathrm{Fe}^{3+}$ ions doped, explaining the magnetic enhancement of $\mathrm{YMn}_{1-\mathrm{x}} \mathrm{Fe}_{\mathrm{x}} \mathrm{O}_{3}(0<\mathrm{x}<0.1)$ samples.

\section{Acknowledgements}

This work is supported by the National Natural Science Foundation of China (U1232133). We are in debt to photoemission spectroscopy experiment station of Beijing Synchrotron Radiation Facility for their help in measuring the XAS spectra.

\section{References}

[1] Spaldin, N.A .and Fiebig, M. (2005) Science, 309, 391. http://dx.doi.org/10.1126/science.1113357

[2] Serrao, C.R., Krupanidhi, S.B., Bhattacharjee, J., Waghmare, U.V., Kundu, A.K. and Rao, C.N.R. (2006) J. Appl. Phys., 100, 076104. http://dx.doi.org/10.1063/1.2356093

[3] Lee, S., Pirogov, A., Han, J.H., Park, J.G., Hoshikawa, A. and KaMiyama, T. (2005) Phys. Rev. B, 71, 180413. http://dx.doi.org/10.1103/PhysRevB.71.180413

[4] Nugroho, A., Bellido, N., Adem, U., Nenert, G., Simon, Ch., Tjia, M.O., Mostovoy, M. and Palstra, T.T.M. (2007) Phys. Rev. B, 75, 174435. http://dx.doi.org/10.1103/PhysRevB.75.174435

[5] Chatterjee, S. and Nigam, A.K. (2002) Phys. Rev. B, 66, 104403. http://dx.doi.org/10.1103/PhysRevB.66.104403

[6] Park, J. and Lee, S. (2010) Phys. Rev. B, 82, 054428. http://dx.doi.org/10.1103/PhysRevB.82.054428

[7] Asokan, K., Chen, Y.S., Pao, C.W., Tsai, H.M., Lee, C.W.O., Lin, C.H., Hsueh, H.C., et al. (2009) Appl. Phys. Lett., 95, 131901. http://dx.doi.org/10.1063/1.3224905

[8] Namdeo, S., Sinha, A.K., Singh, M.N. and Awasthi, A.M. (2013) J. Appl. Phys., 113, 104101. http://dx.doi.org/10.1063/1.4794831

[9] Asaka, T., Nemoto, K., Kimoto, K., Arima, T. and Matsui, Y. (2005) Phys. Rev. B, 71, 014114. http://dx.doi.org/10.1103/PhysRevB.71.014114

[10] Park, J., Kang, M., Kim, J., Lee, S., Jang, K.H., Pirogov, A., Park, J.G., et al. (2009) Phys. Rev. B, 79, 064417. http://dx.doi.org/10.1103/PhysRevB.79.064417

[11] Yoo, Y.J., Lee, Y.P., Park, J.S., Kang, J.H., Kim, J., Lee, B.W. and Seo, M.S. (2012) J. Appl. Phys., $112,013903$. http://dx.doi.org/10.1063/1.4731631

[12] Cho, D.Y., Kim, J.Y., Park, B.G., Rho, K.J., Park, J.H., Noh, H.J., et al. (2007) Phys. Rev. L, 98, 217601. http://dx.doi.org/10.1103/PhysRevLett.98.217601

[13] Van Aken, B.B., Palstra, T.T.M., et al. (2004) Nat. Mater., 3, 164. http://dx.doi.org/10.1038/nmat1080 